\title{
REVIEW
}

\section{Infections in Cancer Patients with Solid Tumors: A Review}

\author{
Kenneth V. I. Rolston
}

Received: December 5, 2016/Published online: February 3, 2017

(C) The Author(s) 2017. This article is published with open access at Springerlink.com

\section{ABSTRACT}

Solid tumors are much more common than hematologic malignancies. Although severe and prolonged neutropenia is uncommon, several factors increase the risk of infection in patients with solid tumors, and the presence of multiple risk factors in the same patient is not uncommon. These include obstruction (most often caused by progression of the tumor), disruption of natural anatomic barriers such as the skin and mucosal surfaces, and treatment-related factors such as chemotherapy, radiation, diagnostic and/or therapeutic surgical procedures, and the increasing use of medical devices such as various catheters, stents, and prostheses. Common sites of infection include the skin and skin structures (including surgical site infections), the bloodstream (including infections associated with central venous catheters), the lungs, the hepato-biliary and intestinal tracts, and the urinary tract, and include distinct

Enhanced content To view enhanced content for this article go to http://www.medengine.com/Redeem/ 0587F0605A2B8227.

K. V. I. Rolston $(\bowtie)$

The Department of Infectious Diseases, Infection Control and Employee Health, The University of Texas MD Anderson Cancer Center, Houston, TX, USA

e-mail: krolston@mdanderson.org clinical syndromes such as post-obstructive pneumonia, obstructive uropathy, and neutropenic enterocolitis. The epidemiology of most of these infections is changing with resistant organisms [MRSA, Pseudomonas aeruginosa, extended spectrum beta-lactamase (ESBL)-producing organisms] being isolated more often than in the past. Polymicrobial infections now predominate when deep tissue sites are involved. Conservative management of most of these infections (antibiotics, fluid and electrolyte replacement, bowel rest when needed) is generally effective, with surgical intervention being reserved for the drainage of deep abscesses, or to deal with complications such as intestinal obstruction or hemorrhage. Infected prostheses often need to be removed. Reactivation of certain viral infections (HBV, HCV, and occasionally $\mathrm{CMV}$ ) has become an important issue, and screening, prevention and treatment strategies are being developed. Infection prevention, infection control, and antimicrobial stewardship are important strategies in the overall management of infections in patients with solid tumors. Occasionally, infections mimic solid tumors and cause diagnostic and therapeutic challenges.

Keywords: Antimicrobial stewardship; Changing epidemiology; Chemotherapy; Infections; Low risk; Obstruction; Radiation; Resistance; Solid tumors; Surgery 


\section{INTRODUCTION}

The National Cancer Institute has defined solid tumors as non-cystic masses (either benign or malignant) including carcinomas, lymphomas, and sarcomas. It has been estimated that $1,685,210$ new cases of cancer will be diagnosed in the United States in 2016, with an estimate of more than 14 million new cases worldwide [1]. The vast majority will be solid tumors with cancers of the breast, lungs and bronchus, prostate, colon and rectum, and urinary bladder being the most common, whereas leukemias will account for approximately $4 \%$ of new cases. Infections are the most common complications seen in cancer patients, and occur as a result of the underlying malignancy and of the various modalities used for treatment. Despite the fact that solid tumors are far more common, infections in patients with solid tumors have not been studied as well as in patients with hematologic malignancies [2, 3]. Unlike the latter, most patients with solid tumors are not significantly immunosuppressed and do not experience prolonged periods of neutropenia. Instead, factors that increase the risk of infection in these patients include damage to normal anatomic barriers, such as the skin and mucosal surfaces, obstructive phenomena (common in patients with lung, hepato-biliary, pancreatic, intestinal, prostatic and gynecologic tumors), surgical procedures, chemotherapy, radiation, central nervous system dysfunction, nutritional factors, and the increasing use of medical devices (catheters, stents, shunts, and prostheses) [4]. Common sites of infection include the respiratory tract, the bloodstream (including central line-associated bloodstream infections), the urinary tract, and skin and skin structures (including surgical site infections). In recent years, the epidemiology of most of these infections has changed with the emergence of resistant organisms. Consequently, newer therapeutic approaches need to be developed based on local epidemiologic and susceptibility/resistance data. Additionally, infection prevention, infection control, and antimicrobial stewardship are important and often underrated and neglected strategies in this setting [5].

\section{Compliance with Ethics Guidelines}

This article is based on previously conducted studies and does not involve any new studies of human or animal subjects performed by any of the authors.

\section{RISK FACTORS FOR INFECTION}

As indicated above, several factors increase the risk of infection in solid tumor patients (Table 1). The presence of multiple risk factors in the same patient is not uncommon, further increasing risk. These factors are discussed in detail below.

\section{Neutropenia}

Neutropenia is defined as an absolute neutrophil count (ANC) of $<500$ cells $/ \mathrm{mm}^{3}$. The most frequent cause of neutropenia is antineoplastic chemotherapy. Varying degrees of neutropenia also occur after radiation therapy or the administration of other myelosuppressive agents (e.g., ganciclovir), and occasionally after extensive infiltration of the bone marrow by spreading tumor. Unlike patients with hematologic malignancies, most patients with solid tumors have normally functioning neutrophils. Additionally, conventional chemotherapy rarely produces severe neutropenia lasting longer than 7 days. Consequently, the "at risk" period is generally short and many solid tumor patients who develop neutropenic fever are considered low risk [6, 7]. Newer treatment strategies for low-risk neutropenic patients have been developed and include early discharge after a short period of hospitalization, or management of the entire episode of neutropenic fever without hospitalization [8-10]. Specific guidelines for the management of febrile neutropenic patients with underlying solid tumors have recently been published [11]. These guidelines stress the importance of performing risk assessment in order to identify low-risk patients who can be treated in an ambulatory setting, since hospitalization is associated with several drawbacks including iatrogenic errors 
Table 1 Factors that increase the risk of infection in patients with solid tumors

\begin{tabular}{|c|c|}
\hline Risk factor $(\mathbf{s})^{\mathbf{a}}$ & Additional explanatory comments \\
\hline Neutropenia & $\begin{array}{l}\text { Chemotherapy, radiation therapy, bone marrow infiltration with tumor, drugs } \\
\text { (e.g., ganciclovir) }\end{array}$ \\
\hline $\begin{array}{l}\text { Disruption of anatomic barriers (e.g., } \\
\text { skin, mucosal surfaces) }\end{array}$ & $\begin{array}{l}\text { Chemotherapy (mucositis), radiation therapy, vascular access catheters, urinary } \\
\text { catheters, percutaneous endoscopic gastrostomy tubes and other medical } \\
\text { devices, surgical/diagnostic procedures }\end{array}$ \\
\hline \multirow[t]{4}{*}{$\begin{array}{l}\text { Obstruction due to primary or } \\
\text { metastatic tumor }\end{array}$} & $\begin{array}{l}\text { Airways: post-obstructive pneumonia, lung abscess, empyema, fistula formation } \\
\text { (e.g., broncho-pleural or trachea-esophogeal) }\end{array}$ \\
\hline & Biliary tract: ascending cholangitis, hepatic and pancreatic abscess \\
\hline & Bowel: bowel obstruction, necrosis, perforation, peritonitis, hemorrhage \\
\hline & Urinary tract: urinary tract infection, renal abscess, prostatitis or prostatic abscess \\
\hline \multirow[t]{3}{*}{ Procedure and devices } & $\begin{array}{l}\text { Diagnostic/therapeutic surgery: surgical site infections, wound dehiscence, abscess } \\
\text { formation }\end{array}$ \\
\hline & $\begin{array}{l}\text { Shunts: disseminated infection (bacteremia) shunt-related infections such as } \\
\text { meningitis/ventriculitis, hepato-biliary infections, complicated urinary tract } \\
\text { infections }\end{array}$ \\
\hline & $\begin{array}{l}\text { Prosthetic devices: infected prosthesis, osteomyelitis and/or septic arthritis, local } \\
\text { abscess formation, disseminated infection }\end{array}$ \\
\hline Miscellaneous factors & Age, nutritional status, prior antibiotic exposure, loss of gag reflex \\
\hline
\end{tabular}

${ }^{a}$ Multiple risk factors frequently occur in the same patient

and exposure to healthcare associated, multidrug-resistant microflora. Safety, however, is paramount, and ambulatory/outpatient management should only be implemented if the appropriate infrastructure to support this activity around the clock exists $[9,10]$.

\section{Disruption of Anatomic Barriers}

Normal anatomic barriers such as the skin and various mucosal surfaces (oro-pharyngeal, gastro-intestinal, respiratory, and genito-urinary) provide an important natural defense mechanism against invading pathogens. Cancer chemotherapy often damages mucosal surfaces, thereby increasing the risk of infections caused by organisms that colonize these surfaces [e.g., viridans group streptococci (VGS), Streptococcus pneumoniae, Stomatococcus mucilaginosus, enteric Gram-negative bacilli, and anaerobes]. Agents that frequently cause mucositis include 5-fluorouracil (5-FC), capecitabine (a pro-drug of 5-FU), cyclophosphamide, ifosfamide, cisplatin and carboplatin. The taxanes (docetaxel and paclitaxel) and vinorelbine have also been associated with significant mucositis. Damage to mucosal barriers is also caused by radiation therapy, surgical procedures, and the use of medical devices. Tumors may cause local erosion and fistula formation (e.g., broncho-pleural, trachea-esophageal, vesico-vaginal or recto-vaginal). Protection provided by the skin is also breached by surgical procedures and radiation, and by medical devices such as catheters and percutaneous endoscopic gastrostomy (PEG)-tubes [12].

\section{Obstruction of Normal Passages}

Obstruction caused by expanding tumors is relatively common in solid tumor patients. Bronchogenic carcinomas (or metastatic 
pulmonary lesions) often cause airways obstruction leading to the development of post-obstructive pneumonia, which may occasionally be the initial manifestation of these tumors [13]. As obstruction increases, lung abscess, fistula formation, or empyema may occur [14]. Biliary tract obstruction in patients with hepato-biliary and pancreatic tumors results in ascending cholangitis and hepatic abscess formation. Ureteral obstruction resulting in hydronephrosis and complicated urinary tract infection is commonplace in patients with carcinoma of the cervix and other gynecologic tumors. Patients with prostatic carcinoma also develop prostatitis, complicated urinary tract infections, and occasionally prostatic abscesses. Intestinal tumors can lead to partial or complete bowel obstruction, ileus, perforation, peritonitis, hemorrhage, and/or abdominal/pelvic abscess formation. In these situations, mixed or polymicrobial infections are the norm, and the etiologic agents are generally those that colonize the site of obstruction.

\section{Procedures and Devices}

Surgery, medical procedures, radiation therapy, and the widespread and increasing use of catheters and other devices is often associated with the development of infection [15]. The use of multiple-lumen vascular access catheters has become commonplace and greatly facilitates the drawing of blood and the administration of various entities such as chemotherapy, antimicrobial agents, blood and blood products, and fluids. The major complication associated with these catheters is infection. The organisms causing catheter-related infections are predominantly those that colonize human skin. Approximately $70-80 \%$ are Gram-positive, with Staphylococcus species being isolated most often. Gram-negative organisms and fungi (mostly Candida spp.) are much less common, and $5-10 \%$ of these infections are polymicrobial. Urinary catheters are used when obstruction or urinary incontinence is present. Occasionally, local involvement of the ureters or urinary bladder may require the creation of surgical diversions into ileal or colonic segments. Acute or chronic pyelonephritis, sometimes progressing to bacteremia (urosepsis), may occur. The use of nephrostomy tubes may be associated with similar complications [16]. Many patients with central nervous system (CNS) tumors require the placement of shunts in order to relieve intracranial pressure. When infected, the CNS end of these shunts produce symptoms such as headache, mental status changes, and meningismus, whereas the distal ends of these shunts (which are generally located in the pleural or peritoneal cavities) give rise to symptoms of pleuritis or peritonitis. Surgically implanted prosthetic devices are used often in patients with osteosarcoma or other bone/cartilage tumors. Infection is the most common complication associated with these devices, and may require removal of the device for resolution of the infection. Patients with head and neck and esophageal cancers often require the placement of PEG-tubes in order to ensure adequate nutrition. Insertion site infections, abdominal wall infections/abscesses, perforation with peritonitis, and occasionally bacteremic infections may occur, but are uncommon [12].

\section{Miscellaneous Factors}

Patients with CNS tumors often develop partial loss of the gag reflex which predisposes them to aspirate oro-pharyngeal secretions. Neurologic abnormalities resulting in impaired micturition can also occur. Radiation can damage ciliary function resulting in aspiration and pneumonia. In elderly patients, immunologic deficits caused by ageing, malnutrition, and cancer cachexia may also have an impact on the frequency and severity of infection and the overall response to therapy. Prior or concurrent antimicrobial usage can result in the selection of resistant organisms. Antimicrobial stewardship and strict adherence to infection control recommendations and policies are important tools in limiting the emergence and spread of such infections.

\section{COMMON SITES OF INFECTION}

Common sites of infection largely depend on the location and size of the tumor and/or the 
site and nature of the medical device in use, the surgical procedure performed, and the site and intensity of radiation (Table 2). Surgical site infections are among the most common. Recent data indicate that the epidemiology of these infections has changed significantly. Whilst Gram-positive organisms still predominate, the proportion caused by methicillin-resistant $S$. aureus (MRSA) has increased substantially compared to 10-15 years ago. Additionally, Gram-negative and polymicrobial surgical site infections appear to be increasing [17]. These changes require modifications to current recommendations for infection prevention and treatment.

Bloodstream infections, including those associated with central venous catheters and other vascular access devices, are among the most common infections seen in solid tumor patients [18]. The spectrum of these infections is changing with an increased frequency of Gram-negative bacilli, many of which are multidrug-resistant, being reported [18]. The lungs represent one of the most common sites of infection in patients with solid tumors [19]. As previously mentioned, aspiration pneumonia is common in patients with impaired gag reflex and/or ciliary function, whereas post-obstructive pneumonia is common in patients with primary or metastatic lung cancers. Infections involving the hepato-biliary and gastro-intestinal tracts also occur frequently and are associated with a common set of manifestations which may give rise to diagnostic and therapeutic challenges [20]. Obstructive uropathy and complicated urinary tract infections go hand in hand and are often recurrent and difficult to eradicate. Specific infections/syndromes at these sites will be discussed in greater detail below.

Table 2 Common sites of infection in patients with solid tumors

\begin{tabular}{|c|c|}
\hline Infection site & Comments \\
\hline Bloodstream & $\begin{array}{l}\text { Often associated with vascular access catheters and neutropenia. Changing epidemiology, with } \\
\text { resistant Gram-negative organisms emerging }\end{array}$ \\
\hline Breast & $\begin{array}{l}\text { Generally related to breast cancer surgery, including reconstruction and implants. Changing } \\
\text { epidemiology with MRSA and Gram-negative organisms common }\end{array}$ \\
\hline Bone, cartilage, joints & $\begin{array}{l}\text { Often surgery- or prosthetic device-related. May require device removal and/or long-term } \\
\text { suppressive therapy }\end{array}$ \\
\hline Central nervous system & Including ventriculitis, meningitis, shunt-related infections, and post-surgical infections \\
\hline Skin and skin structure & $\begin{array}{l}\text { Most often related to surgery, including invasive diagnostic procedures. May be chronic or } \\
\text { persistent in irradiated areas. Poly-microbial infections are common }\end{array}$ \\
\hline Respiratory tract & $\begin{array}{l}\text { Aspiration pneumonia in patients with loss of gag reflex or ciliary function. Post-obstructive } \\
\text { pneumonia (with empyema or fistula formation with progressive disease) }\end{array}$ \\
\hline Hepato-biliary pancreatic & $\begin{array}{l}\text { Ascending cholangitis ( } \pm \text { bacteremia); local abscess formation, reactivation of viral infections } \\
(\mathrm{HBV}, \mathrm{HCV}, \mathrm{CMV})\end{array}$ \\
\hline Upper gastro-intestinal & $\begin{array}{l}\text { Tracheo-esophageal fistula; percutaneous endoscopic gastrostomy (PEG)-tube-related infection, } \\
\text { gastric perforation with abscess formation or peritonitis }\end{array}$ \\
\hline $\begin{array}{l}\text { Lower gastro-intestinal, } \\
\text { pelvic }\end{array}$ & $\begin{array}{l}\text { Bowel perforation with peritonitis or abscess formation, neutropenic enterocolitis, Clostridium } \\
\text { difficile- or CMV-associated colitis; perirectal/peri-anal infection }\end{array}$ \\
\hline $\begin{array}{l}\text { Genitourinary tract and } \\
\text { prostate }\end{array}$ & $\begin{array}{l}\text { Complicated urinary tract infections; obstructive uropathy; prostatitis; abdominal and/or pelvic } \\
\text { abscesses }\end{array}$ \\
\hline
\end{tabular}




\section{CURRENT MICROBIOLOGY OF INFECTION}

Most infections in patients with solid tumors are caused by the individual patients' resident microflora. Consequently, the distribution of causative organisms mirrors the normal microflora at a particular site of infection [4, 21]. Acquisition of nosocomial or healthcare-associated pathogens generally occurs several days after hospitalization, although, in recent years, the site of care has shifted to a great extent to clinics and out-patient oncology centers, wherein healthcare-associated infections are also commonplace. Prolonged or multiple antibiotic exposure, which often occurs in solid tumor patients, leads to the selection of resistant organisms. Geographic and local (institutional) differences in microbiology and susceptibility/resistance patterns are not infrequent and must always be taken into account when choosing empiric treatment regimens.

\section{SPECIFIC SYNDROMES/SITES OF INFECTION}

\section{Bloodstream Infections}

Bloodstream infections occur predominantly in patients with indwelling central venous catheters and other vascular access devices as well as in patients with significant oral or intestinal mucositis. Bloodstream infections are more common in such patients when they develop episodes of neutropenia. Unlike patients with hematologic malignancies, most patients with solid tumors do not receive antimicrobial prophylaxis following chemotherapy. Such prophylaxis is directed primarily against Gram-negative organisms. Consequently, in the absence of prophylaxis, Gram-negative BSIs are more common than Gram-positive BSIs in patients with solid tumors. [18]. Escherichia coli, Klebsiella species, and Pseudomonas aeruginosa are the most common Gram-negative species isolated [22]. Non-fermentative Gram-negative bacilli are emerging as significant pathogens at some institutions. These include Acinetobacter species, Stenotrophomonas maltophilia, Achromobacter species, and non-aeruginosa Pseudomonas species, many of which are multidrug-resistant [23]. Staphylococci, streptococci, and enterococci are the predominant Gram-positive pathogens isolated. At many institutions, more than $90 \%$ of coagulase-negative staphylococci (CoNS) and more than 50\% of $S$. aureus are methicillin-resistant, and 15-20\% of Enterococcus species are vancomycin-resistant. A minority of BSIs are fungal, caused almost exclusively by Candida species. Anaerobes are seldom isolated from blood cultures.

\section{Post-obstructive Pneumonia}

Post-obstructive pneumonia is defined as infection of the lung parenchyma caused by bronchial obstruction [24]. In most cases, the obstruction is caused by a neoplasm, and post-obstructive pneumonia may be the initial manifestation of malignancy in $40-50 \%$ of patients with this diagnosis [13]. Fever, cough, sputum production, and weight loss are common. Leucocytosis is also common unless chemotherapy-induced myelosuppression is present. Other symptoms include dyspnea, pleuritic chest pain, and hemoptysis. Symptoms persist and worsen as the degree of obstruction increases. Since the infection is located below the level of obstruction, respiratory samples from above this level are often negative. In many cases, Invasive diagnostic procedures such as percutaneous lung aspiration/biopsy may be the most accurate way of determining the etiology. Microbiologic data are often difficult to interpret, and generally reveal polymicrobial flora $[25,26]$. These include Streptococcus species such as $S$. pneumoniae, beta-haemolytic streptococci, and viridans group streptococci; Staphylococcus species including methicillin-resistant isolates, Gram-negative bacilli such as the Enterobacteriaceae and Pseudomonas aeruginosa, and some anaerobes. Candida species are also frequently isolated, but their role in this infection is unclear. Most patients are treated with broad spectrum antimicrobial regimens directed against the pathogens outlined above. 
Despite such therapy, responses are often slow, and complete defervescence generally does not occur, with persistent or recurrent infections being common. Approximately $10-15 \%$ of patients with chronic or progressive post-obstructive pneumonia develop serious complications such as lung abscess, hemorrhage, empyema, and fistula formation (broncho-pleural or trachea-esophageal). A vicious cycle often ensues, as these complications frequently cause delays in the administration of antineoplastic therapy, which can lead to worsening of the obstruction. Consequently, full attention should be focused on treating the lesion(s) causing obstruction. Several options to accomplish this are available including low- or high-dose-rate brachytherapy, cryotherapy, laser therapy, electro-cautery, and the placement of airways stents [27, 28]. Unfortunately, despite these measures, progressive, ultimately fatal, disease is the norm [14].

\section{Infections Associated with Breast Cancer Surgery}

Breast cancer is the most common cancer in women worldwide and its frequency has been increasing in recent years [1, 29-31]. Most of these patients undergo some surgical procedure of the involved breast along with ipsilateral lymph node dissection. Several forms of breast reconstruction are also frequently performed. These include autologous reconstruction using a transverse rectus abdominis musculo-cutaneous flap, or a deep inferior epigastric artery perforator flap [31]. Prosthetic reconstruction using silicone or saline implants is also widely used. Although a detailed discussion of the various surgical/reconstruction procedures is beyond the scope of this review, all these procedures are associated with an infection rate that ranges between $2.5 \%$ and $24 \%$ [32, 33]. Infection is a leading cause of hospital admission in such patients, and can result in devastating medical/surgical, psycho-social, and financial consequences. Factors that increase the risk of infection include increased body mass index, radiation therapy (which also retards healing), axillary lymph node dissection, the use of surgical drains, adjuvant chemotherapy, and possibly tobacco use [34-37]. Staphylococci (CoNS and S. aureus) are involved in almost all such infections, with the majority of isolates being methicillin-resistant. However, several recent studies indicate that a small but significant proportion of these infections are caused by Gram-negative bacilli such as E. coli, P. aeruginosa, and Klebsiella species [38-40]. Non-tuberculous mycobacterial and polymicrobial infections are less common but are difficult to manage [41]. With a significant rate of, and changing epidemiology of, infection in this setting, infection prevention has become extremely important. Antimicrobial prophylaxis is an important infection prevention strategy. Breast surgery is considered clean surgery by the Center for Disease Control and Prevention (CDC) and the Surgical Care Improvement Project, and current guidelines suggest a maximum of $24 \mathrm{~h}$ of peri-operative antibiotics [42]. Agents commonly used for antimicrobial prophylaxis (predominantly firstand second-generation cephalosporin) were chosen several decades ago and do not provide adequate coverage against organisms (MRSA, $P$. aeruginosa) mentioned above [39, 43]. Several investigators have recommended alternative regimens based on local epidemiology and susceptibility/resistance patterns [44-46]. Since most of the procedures are elective, some recommend screening patients for MRSA and $P$. aeruginosa and providing targeted prophylaxis when these organisms are detected, or using agents with activity against these organisms in empiric regimens [47-49].

\section{Hepato-biliary Infection}

Obstruction of the biliary tract as a result of hepato-biliary or pancreatic tumors results in the development of ascending cholangitis [50]. Less frequently, single or multiple liver abscesses develop, especially in patients with persistent obstruction [51]. These are being documented with increasing frequency due to improved imaging techniques. As with lung neoplasms and post-obstructive pneumonia, ascending cholangitis may be the initial 
manifestation of local neoplastic disease, and may lead to its discovery during evaluation. Hepatic abscesses have also been reported after invasive procedures for hepatocellular carcinoma, such as the administration of intra-arterial chemotherapy [52, 53]. Most of these infections are polymicrobial, with enteric Gram-negative bacilli, Enterococcus species (including VRE), and anaerobes being predominant [54]. Broad spectrum antimicrobial therapy and percutaneous drainage are often necessary in order to achieve adequate responses. Patients with hepatocellular carcinoma and pancreatic head tumors often develop obstructive jaundice, which can progress to hepatic failure. In this setting, percutaneous transhepatic biliary drainage (PTBD) has been used to treat obstructive jaundice [55]. More recently, endoscopic biliary stenting (EBS) is replacing PTBD as the treatment of choice in this setting [56]. Several studies have shown that internal biliary drainage increases microbial colonization of stents and the formation of sludge which also contains intestinal microorganisms [57]. The frequency of cholangitis appears to be increased in such circumstances $[57,58]$.

\section{Infections Involving the Intestinal Tract}

The intestinal tract is a common site of infection in patients with solid tumors. Several well-recognized syndromes have been described in such patients, including appendicitis, intestinal perforation with peritonitis and/or local abscess formation, Clostridium difficile-associated colitis, cytomegalovirus (CMV) colitis, and typhlitis or neutropenic enterocolitis [20]. The clinical manifestations associated with most of these syndromes are similar, and include abdominal symptoms (cramping, pain, tenderness, distension), fever, diarrhea, and intestinal hemorrhage. These manifestations are not typical nor pathognomonic of any single entity. Therefore, clinical features, radiographic imaging findings, microbiologic, serologic, and histopathologic data need to be considered in order to make a specific diagnosis. Conservative medical management (fluid and electrolyte support, bowel rest, broad-spectrum parenteral antibiotic therapy) is generally effective. Surgical intervention is usually needed when complications such as intestinal perforation or bleeding develop.

In years gone by, neutropenic enterocolitis (NEC) was seen primarily in patients with acute leukemia receiving intensive cytotoxic chemotherapy with agents such as cytosine arabinoside or idarubicin [59-61]. NEC was documented much less often in patients with solid tumors. Recent reports have highlighted an association between NEC and therapy with taxanes (docetaxel, paclitaxel) and vinorelbine [62-64]. These agents are often used to treat solid tumors such as breast, lung, and ovarian cancers. Pre-existing bowel abnormalities such as diverticulosis/diverticulitis, bowel infiltration with the underlying tumor, and prior surgery or radiation may also increase the risk of development of NEC following cytotoxic chemotherapy. The onset of NEC usually occurs in the third week of neutropenia (median 17 days) and coincides with maximal mucosal damage. However, there are reports suggesting earlier or later onset, sometimes even after resolution of neutropenia. In patients with the abdominal symptoms outlined above, imaging studies are the most reliable and accurate tools for making a diagnosis of NEC. Computerized tomography (CT) is the imaging option of choice [65]. The most characteristic CT finding is bowel wall thickening, usually around $7 \mathrm{~mm}$ (range $4-15 \mathrm{~mm}$ ). An important prognostic finding is the presence of bowel wall thickening of $>10 \mathrm{~mm}$ which is associated with severe disease and poorer outcomes [66]. As mentioned previously, general supportive measures such as bowel rest with nasogastric suction and parenteral nutrition if necessary, along with fluid and electrolyte replenishment, are generally effective, with surgical intervention being reserved for more serious complications.

Risk factors associated with $C$. difficile colonization and disease include antibiotic usage, proton-pump inhibitors or $\mathrm{H} 2$ blockers, previous hospitalization, and antineoplastic chemotherapy [67]. Up to $6 \%$ of patients receiving cisplatin therapy for ovarian carcinoma develop C. difficile-associated colitis [68]. 
Such therapy should subsequently be avoided since relapse or recurrent infection can occur [69]. Recent data suggest that vancomycin is superior to metronidazole therapy for moderate to severe infection. Fidaxomicin, a new macrocyclic agent, is similar to vancomycin with regards to clinical response, but produces more sustained responses and fewer relapses [70-72]. Fecal microbiota transplantation has been shown to be efficacious in patients with multiple recurrences [73].

CMV disease has not been well studied in solid tumor patients. Although infrequently reported, CMV testing is not routinely performed in such patients, consequently reactivation of CMV or active disease is probably often unrecognized and underreported. One retrospective analysis reported that at least 50\% of patients with solid tumors with a positive CMV polymerase chain reaction also had clinically relevant $\mathrm{CMV}$ disease requiring antiviral therapy [74]. Although gastrointestinal CMV disease is uncommon in patients with solid tumors, it is associated with high morbidity and mortality [75].

\section{Hepatitis}

Hepatitis virus infections (both hepatitis B virus, $\mathrm{HBV}$, and hepatitis $\mathrm{C}$ virus, $\mathrm{HCV}$ ) are relatively common worldwide. Recent estimates suggest that more than 350 million individuals globally have HBV infection and 130-170 million are infected with HCV [76-78]. In oncology settings, HBV reactivation rates vary between $30 \%$ and $80 \%$ depending on the HBV serologic status and the specific chemotherapy regimen [79]. Whilst reactivation can be asymptomatic, it can lead to severe hepatitis, liver failure and death [80]. It often leads to delays in antineoplastic chemotherapy which can result in increased tumor-related mortality. Patients with solid tumors who are hepatitis B surface antigen (HBsAg)- or hepatitis B core antibody ( $\mathrm{HBcAb}$ )-positive are at risk for $\mathrm{HBV}$ reactivation after the administration of cytotoxic chemotherapy. The CDC recommends universal screening of individuals prior to the administration of cytotoxic chemotherapy or immunosuppressive therapy [81]. A recent systematic review and meta-analysis of HBV reactivation and prophylaxis during chemotherapy for solid tumors concluded that, in patients with chronic HBV receiving such chemotherapy, the risk of reactivation was similar to other types of immunosuppressive therapy, and that there was strong support for HBV screening and antiviral prophylaxis prior to initiating such therapy [82]. Other studies/groups have confirmed these findings [83, 84]. Preferred agents for HBV prophylaxis include lamivudine, entecavir, and tenofovir. Additionally, monitoring of viral load and hepatic transaminases is recommended for patients who do not have active HBV infection and are not receiving prophylaxis [85].

$\mathrm{HCV}$ reactivation in cancer patients has not been as well studied as HBV reactivation. The overall prevalence of $\mathrm{HCV}$ infection in cancer patients ranges from $1.5 \%$ to $32 \%[86,87]$. However, very little is known about its natural history, prophylaxis, treatment, and outcomes in this patient population. HCV-positive patients with cancer have a higher risk of developing cirrhosis, progress to fibrosis more rapidly, and have poorer virologic responses [88]. Increased mortality has been reported in patients with cancer who have $\mathrm{HCV}$ infection compared to those who do not [89]. Additionally, increased risk of reactivation has also been reported in patients receiving targeted therapies [90]. Although treatment and outcomes data in cancer patients are limited, in the general population HCV therapy can cure infection, prevent reactivation, delay progression to cirrhosis, and reduce overall mortality [91, 92]. Guidelines recently issued by the National Comprehensive Cancer Network state that all patients receiving chemotherapy or immunosuppressive therapy should be screened for HCV [85]. Although no specific treatment guidelines for cancer patients exist, HCV therapy in this setting has been shown to be feasible and to prevent or decrease progression of liver disease. An algorithm for the management of patients with cancer and HCV infection has recently been published [86]. 


\section{Obstructive Uropathy/Complicated Urinary Tract Infections}

Obstructive uropathy is common in patients with solid tumors [16]. The resultant urinary stasis leads to bacterial colonization and can progress to the development of complicated urinary tract infection and urosepsis. Acute or chronic ureteral obstruction (most often unilateral but occasionally bilateral) is a complication of advancing retroperitoneal or pelvic malignancy. Prompt decompression of the obstruction is required. Ureteral stents have been used for the management of ureteral obstruction in this setting. Silicone or polyurethane stents are most often used but may be associated with significant failure rates. Metallic stents have also been evaluated and are considered to be effective [16, 93-95]. Alternatively, obstructions can be dealt with the placement of percutaneous nephrostomy tubes. The use of stents and nephrostomy tubes is associated with a significant rate of pyelonephritis [16]. Organisms causing these infections include Staphylococcus species, Enterococcus species, E. coli, P. aeruginosa, S. maltophilia, Klebsiella species, and Candida species [16]. Eradication of such infections is difficult to accomplish and recurrent infections are the norm. Long-term suppressive antibiotic therapy may be necessary in patients who develop frequent bouts of urosepsis.

\section{INFECTIONS MIMICKING CANCER}

Occasionally, certain infections produce clinical manifestations and/or radiographic images that cannot be readily distinguished from those produced by neoplasms. When such lesions are detected, the most common suspicion is that of metastatic or recurrent neoplasm, but, in a small proportion of patients, are caused by an infection. These lesions also need to be evaluated promptly and a specific etiology established, since the management of recurrent neoplastic disease is totally different from that of infection.

\section{SUMMARY}

Patients with hematologic malignancies often develop infections, especially during episodes of neutropenia. Since this is a relatively homogenous group of patients compared to patients with solid tumors, it has been well studied. Several societies have developed and published guidelines for the management of neutropenic patients $[8,9,85,96]$. Infections also represent a

Table 3 Infection-related clinical syndromes commonly seen in patients with solid tumors

\begin{tabular}{ll}
\hline Clinical syndrome & Comments \\
\hline Post-obstructive pneumonia & $\begin{array}{r}\text { Frequent in patients with primary or metastatic lung lesions. Sometimes the initial } \\
\text { manifestation of malignancy. Complications include lung abscess, fistula formation, or } \\
\text { empyema. Treatment failures common }\end{array}$ \\
Obstructive uropathy & $\begin{array}{l}\text { Common in patients with genitourinary and prostatic tumors. Complicated urinary tract } \\
\text { infections and multidrug-resistant organisms are frequent }\end{array}$ \\
Reactivation of viral & $\begin{array}{l}\text { Hepatitis B virus and hepatitis C virus, usually following chemotherapy or } \\
\text { infections }\end{array}$ \\
immunosuppressive therapy. Screening for all patients scheduled to receive chemotherapy is \\
recommended as is HBV prophylaxis for patients with HBV infection \\
associated disease & $\begin{array}{l}\text { Multiple risk factors (antibiotics, chemotherapy, local anatomical factors). Recurrent } \\
\text { infections/relapses common. Newer therapies (fidaxomicin, fecal microbiota } \\
\text { transplantation) have been developed }\end{array}$ \\
Neutropenic enterocolitis & $\begin{array}{l}\text { Associated with taxanes (docetaxel and paclitaxel), vinorelbine, and other agents producing } \\
\text { severe mucositis }\end{array}$ \\
\hline
\end{tabular}


significant problem in patients with solid tumors and this is a much more heterogenous group. These infections are quite different from the infections seen in patients with hematologic malignancies, especially those with neutropenia, and have generally been less well studied. Many of these infections are related to the tumor itself, due mostly to obstruction or disruption of natural anatomic barriers. Others are related to various treatment modalities (chemotherapy, radiation, surgery, targeted therapies). Recent data regarding many aspects of such infections are scant. This review provides an update and discusses in detail syndromes such as NEC, post-obstructive pneumonia, breast cancer surgery-related infections, and reactivation of hepatitis virus infections, which have either become more common or are being newly described/studied in solid tumor patients (Table 3). The changing epidemiology of infections, with the emergence of resistant organisms has been highlighted, and the role of infection control in preventing the spread of such infections, as well as the role of antimicrobial stewardship in preserving the useful life of antimicrobial agents, has been stressed. Very rarely, certain infections may mimic cancer. These conditions need to be differentiated promptly so that appropriate therapy can be delivered.

\section{ACKNOWLEDGEMENTS}

No funding or sponsorship was received for this study or publication of this article. All named authors meet the International Committee of Medical Journal Editors (ICMJE) criteria for authorship for this manuscript, take responsibility for the integrity of the work as a whole, and have given final approval for the version to be published.

Disclosures. Kenneth V. I. Rolston has nothing to disclose.

Compliance with Ethics Guidelines. This article is based on previously conducted studies and does not involve any new studies of human or animal subjects performed by any of the authors.

Open Access. This article is distributed under the terms of the Creative Commons Attribution-NonCommercial 4.0 International License (http://creativecommons.org/licenses/ by-nc/4.0/), which permits any noncommercial use, distribution, and reproduction in any medium, provided you give appropriate credit to the original author(s) and the source, provide a link to the Creative Commons license, and indicate if changes were made.

\section{REFERENCES}

1. Siegel RL, Miller KD, Jemal A. Cancer statistics, 2016. CA Cancer J Clin. 2016;66:7-30.

2. Chizuka A, Suda M, Shibata T, et al. Difference between hematological malignancy and solid tumor research articles published in four major medical journals. Leukemia. 2006;20:1655-7.

3. Avritscher EB, Cooksley CD, Rolston KV, et al. Serious postoperative infections following resection of common solid tumors: outcomes, costs, and impact of hospital surgical volume. Support Care Cancer. 2014;22:527-35.

4. Gudiol C, Aguado JM, Carratalà J. Bloodstream infections in patients with solid tumors. Virulence. 2016;7:298-308.

5. Tverdek FP, Rolston KV, Chemaly RF. Antimicrobial stewardship in patients with cancer. Pharmacotherapy. 2012;32:722-34.

6. Klastersky J, Paesmans M, Rubenstein EB, et al. The Multinational Association for Supportive Care in Cancer risk index: a multinational scoring system for identifying low-risk febrile neutropenic cancer patients. J Clin Oncol. 2000;18:3038-51.

7. Kern WV. Risk assessment and treatment of low-risk patients with febrile neutropenia. Clin Infect Dis. 2006;42:533-40.

8. Freifeld AG, Bow EJ, Sepkowitz KA, et al. Clinical practice guideline for the use of antimicrobial agents in neutropenic patients with cancer: 2010 update by the infectious diseases society of America. Clin Infect Dis. 2011;52:e56-93.

9. Flowers CR, Seidenfeld J, Bow EJ, et al. Antimicrobial prophylaxis and outpatient management of 
fever and neutropenia in adults treated for malignancy: American Society of Clinical Oncology clinical practice guideline. J Clin Oncol. 2013;31:794-810.

10. Rolston KV. New trends in patient management: risk-based therapy for febrile patients with neutropenia. Clin Infect Dis. 1999;29:515-21.

11. Virizuela JA, Carratalà J, Aguado JM, et al. Management of infection and febrile neutropenia in patients with solid cancer. Clin Transl Oncol. 2016;18:557-70.

12. Rolston KV, Mihu C, Tarrand JJ. Current microbiology of percutaneous endoscopic gastrostomy tube (PEG tube) insertion site infections in patients with cancer. Support Care Cancer. 2011;19:1267-71.

13. Abers MS, Sandvall BP, Sampath R, et al. Postobstructive pneumonia: an underdescribed syndrome. Clin Infect Dis. 2016;62:957-61.

14. Rolston KV. Postobstructive pneumonia in cancer patients. Clin Infect Dis. 2016;63:707-8.

15. Bin Nafisah S, Ahmad M. Ommaya reservoir infection rate: a 6-year retrospective cohort study of Ommaya reservoir in pediatrics. Childs Nerv Syst. 2015;31:29-36.

16. Bahu R, Chaftari AM, Hachem RY, et al. Nephrostomy tube related pyelonephritis in patients with cancer: epidemiology, infection rate and risk factors. J Urol. 2013;189:130-5.

17. Rolston KV, Nesher L, Tarrand JT. Current microbiology of surgical site infections in patients with cancer: a retrospective review. Infect Dis Ther. 2014;3:245-56.

18. Marín M, Gudiol C, Garcia-Vidal C, Ardanuy C, Carratalà J. Bloodstream infections in patients with solid tumors: epidemiology, antibiotic therapy, and outcomes in 528 episodes in a single cancer center. Medicine (Baltimore). 2014;93:143-9.

19. Rolston KV. The spectrum of pulmonary infections in cancer patients. Curr Opin Oncol. 2001;13:218-23.

20. Badgwell BD, Cormier JN, Wray CJ, et al. Challenges in surgical management of abdominal pain in the neutropenic cancer patient. Ann Surg. 2008;248:104-9.

21. Yapici O, Gunseren F, Yapici H, Merdin A, Yaylali Ü, Merdin FA. Evaluation of febrile neutropenic episodes in adult patients with solid tumors. Mol Clin Oncol. 2016;4:379-82.

22. Marin M, Gudiol C, Ardanuy C, et al. Bloodstream infections in neutropenic patients with cancer: differences between patients with haematological malignancies and solid tumours. J Infect. 2014;69:417-23.

23. Rolston KV, Kontoyiannis DP, Yadegarynia D, Raad II. Nonfermentative gram-negative bacilli in cancer patients: increasing frequency of infection and antimicrobial susceptibility of clinical isolates to fluoroquinolones. Diagn Microbiol Infect Dis. 2005;51:215-8.

24. Torres A, Ferrer M. Editorial Commentary: Distinguishing postobstructive lung infection from community-acquired pneumonia. Clin Infect Dis. 2016;62:962-3.

25. Hsu-Kim C, Hoag JB, Cheng GS, Lund ME. The microbiology of postobstructive pneumonia in lung cancer patients. J Bronchol Interv Pulmonol. 2013;20:266-70.

26. Rolston KV, Bodey GP, Safdar A. Polymicrobial infection in patients with cancer: an underappreciated and underreported entity. Clin Infect Dis. 2007;45:228-33.

27. Quint LE. Thoracic complications and emergencies in oncologic patients. Cancer Imaging. 2009;9(Spec No A):S75-82.

28. de Aquino Gorayeb MM, Gregório MG, de Oliveira EQ, Aisen S, Carvalho HA. High-dose-rate brachytherapy in symptom palliation due to malignant endobronchial obstruction: a quantitative assessment. Brachytherapy. 2013;12:471-8.

29. Barr SP, Topps AR, Barnes NL, et al. Infection prevention in breast implant surgery-a review of the surgical evidence, guidelines and a checklist. Eur J Surg Oncol. 2016;42:591-603.

30. Brand JS, Colzani E, Johansson AL, et al. Infection-related hospitalizations in breast cancer patients: risk and impact on prognosis. J Infect. 2016;72:650-8.

31. Quinn TT, Miller GS, Rostek M, Cabalag MS, Rozen WM, Hunter-Smith DJ. Prosthetic breast reconstruction: indications and update. Gland Surg. 2016;5:174-86.

32. Nahabedian MY, Tsangaris T, Momen B, Manson PN. Infectious complications following breast reconstruction with expanders and implants. Plast Reconstr Surg. 2003;112:467-76.

33. Cordeiro PG, McCarthy CM. A single surgeon's 12-year experience with tissue expander/implant breast reconstruction: part II. An analysis of long-term complications, aesthetic outcomes, and patient satisfaction. Plast Reconstr Surg. 2006;118:832-9. 
34. Francis SH, Ruberg RL, Stevenson KB, et al. Independent risk factors for infection in tissue expander breast reconstruction. Plast Reconstr Surg. 2009;124:1790-6.

35. Cordeiro PG, Pusic AL, Disa JJ, McCormick B, VanZee K. Irradiation after immediate tissue expander/ implant breast reconstruction: outcomes, complications, aesthetic results, and satisfaction among 156 patients. Plast Reconstr Surg. 2004;113:877-81.

36. Epstein M, Silverstein M, Lin K, et al. Acute and chronic complications in breast cancer patients treated with intraoperative radiation therapy. Ann Surg Oncol. 2016;23:3304-9.

37. Huo J, Smith BD, Giordano SH, Reece GP, Shih YC. Post-mastectomy breast reconstruction and its subsequent complications: a comparison between obese and non-obese women with breast cancer. Breast Cancer Res Treat. 2016;157:373-83.

38. Seng P, Bayle S, Alliez A, Romain F, Casanova D, Stein A. The microbial epidemiology of breast implant infections in a regional referral centre for plastic and reconstructive surgery in the south of France. Int J Infect Dis. 2015;35:62-6.

39. Rolston KV, Nesher L, Tarrand JT. Current microbiology of surgical site infections in patients with cancer: a retrospective review. Infect Dis Ther. 2014;3:245-256.

40. McCullough MC, Chu CK, Duggal CS, Losken A, Carlson GW. Antibiotic prophylaxis and resistance in surgical site infection after immediate tissue expander reconstruction of the breast. Ann Plast Surg. 2014;73:1-5.

41. Viola GM, Raad II, Rolston KV. Breast tissue expander-related infections: perioperative antimicrobial regimens. Infect Control Hosp Epidemiol. 2014;35:75-81.

42. Mangram AJ, Horan TC, Pearson ML, Silver LC, Jarvis WR, Guideline for Prevention of Surgical Site Infection. Centers for Disease Control and Prevention (CDC) Hospital Infection Control Practices Advisory Committee. Am J Infect Control. 1999;1999(27):97-132.

43. Feldman EM, Kontoyiannis DP, Sharabi SE, Lee E, Kaufman Y, Heller L. Breast implant infections: is cefazolin enough? Plast Reconstr Surg. 2010;126:779-85.

44. Ariyan S, Martin J, Lal A, et al. Antibiotic prophylaxis for preventing surgical-site infection in plastic surgery: an evidence-based consensus conference statement from the American Association of Plastic Surgeons. Plast Reconstr Surg. 2015;135:1723-39.
45. Phillips BT, Bishawi M, Dagum AB, Khan SU, Bui DT. A systematic review of antibiotic use and infection in breast reconstruction: what is the evidence? Plast Reconstr Surg. 2013;131:1-13.

46. Viola GM, Baumann DP, Mohan K, et al. Improving antimicrobial regimens for the treatment of breast tissue expander-related infections. Plast Reconstr Surg Glob Open. 2016;4:e704.

47. Viola GM, Selber JC, Crosby M, et al. Salvaging the infected breast tissue expander: a standardized multidisciplinary approach. Plast Reconstr Surg Glob Open. 2016;4:e732.

48. Cohen JB, Carroll C, Tenenbaum MM, Myckatyn TM. Breast implant-associated infections: the role of the national surgical quality improvement program and the local microbiome. Plast Reconstr Surg. 2015;136:921-9.

49. Weichman KE, Levine SM, Wilson SC, Choi M, Karp NS. Antibiotic selection for the treatment of infectious complications of implant-based breast reconstruction. Ann Plast Surg. 2013;71:140-3.

50. Huang SY, Philip A, Richter MD, Gupta S, Lessne ML, Kim CY. Prevention and management of infectious complications of percutaneous interventions. Semin Interv Radiol. 2015;32:78-88.

51. Shi S, Xia W, Guo H, Kong H, Zheng S. Unique characteristics of pyogenic liver abscesses of biliary origin. Surgery. 2016;159:1316-24.

52. Sun Z, Li G, Ai X, et al. Hepatic and biliary damage after transarterial chemoembolization for malignant hepatic tumors: incidence, diagnosis, treatment, outcome and mechanism. Crit Rev Oncol Hematol. 2011;79:164-74.

53. Shin JU, Kim KM, Shin SW, et al. A prediction model for liver abscess developing after transarterial chemoembolization in patients with hepatocellular carcinoma. Dig Liver Dis. 2014;46:813-7.

54. Rolston KV, Dholakia N, Rodriguez S, Rubenstein EB. Nature and outcome of febrile episodes in patients with pancreatic and hepatobiliary cancer. Support Care Cancer. 1995;3:414-7.

55. Xu C, Lv PH, Huang XE, Wang SX, Sun L, Wang FA. Analysis of different ways of drainage for obstructive jaundice caused by hilar cholangiocarcinoma. Asian Pac J Cancer Prev. 2014;15:5617-20.

56. Sugiyama G, Okabe Y, Ishida Y, et al. Evaluation of endoscopic biliary stenting for obstructive jaundice caused by hepatocellular carcinoma. World J Gastroenterol. 2014;20:6968-73. 
57. Schneider J, Hapfelmeier A, Fremd J, et al. Biliary endoprosthesis: a prospective analysis of bacterial colonization and risk factors for sludge formation. PLoS ONE. 2014;9:e110112.

58. Fujii T, Yamada S, Suenaga M, et al. Preoperative internal biliary drainage increases the risk of bile juice infection and pancreatic fistula after pancreatoduodenectomy: a prospective observational study. Pancreas. 2015;44:465-70.

59. Gorschlüter M, Marklein G, Höfling K, et al. Abdominal infections in patients with acute leukaemia: a prospective study applying ultrasonography and microbiology. Br J Haematol. 2002;117:351-8.

60. Capria S, Vitolo D, Cartoni C, et al. Neutropenic enterocolitis in acute leukemia: diagnostic and therapeutic dilemma. Ann Hematol. 2004;83:195-7.

61. Nesher L, Rolston KVI. Neutropenic enterocolitis, a growing concern in the era of widespread use of aggressive chemotherapy. Clin Infect Dis. 2013;56:711-7.

62. Ibrahim NK, Sahin AA, Dubrow RA, et al. Colitis associated with docetaxel-based chemotherapy in patients with metastatic breast cancer. Lancet. 2000;355:281-3.

63. Kreis W, Petrylak D, Savarese D, Budman D. Colitis and docetaxel-based chemotherapy. Lancet. 2000;355:2164.

64. de Matteis A, Nuzzo F, Rossi E, Landi G, Perrone F. Intestinal side-effects of docetaxel/vinorelbine combination. Lancet. 2000;355:1098-9.

65. Kirkpatrick ID, Greenberg HM. Gastrointestinal complications in the neutropenic patient: characterization and differentiation with abdominal CT. Radiology. 2003;226:668-74.

66. Cartoni C, Dragoni F, Micozzi A, et al. Neutropenic enterocolitis in patients with acute leukemia: prognostic significance of bowel wall thickening detected by ultrasonography. J Clin Oncol. 2001;19:756-61.

67. Loo VG, Bourgault AM, Poirier L, et al. Host and pathogen factors for Clostridium difficile infection and colonization. N Engl J Med. 2011;365:1693-703.

68. Emoto M, Kawarabayashi T, Hachisuga MD, Eguchi F, Shirakawa K. Clostridium difficile colitis associated with cisplatin-based chemotherapy in ovarian cancer patients. Gynecol Oncol. 1996;61:369-72.

69. Allen VA, Manahan KJ, Geisler JP. Recurrent pseudomembranous colitis in an ovarian cancer patient undergoing carboplatin chemotherapy. Case Rep Obstet Gynecol. 2016;2016:7540302.

70. Penziner S, Dubrovskaya Y, Press R, Safdar A. Fidaxomicin therapy in critically ill patients with Clostridium difficile infection. Antimicrob Agents Chemother. 2015;59:1776-81.

71. Cornely OA, Nathwani D, Ivanescu C, Odufowora-Sita O, Retsa P, Odeyemi IA. Clinical efficacy of fidaxomicin compared with vancomycin and metronidazole in Clostridium difficile infections: a meta-analysis and indirect treatment comparison. J Antimicrob Chemother. 2014;69:2892-900.

72. Zhanel GG, Walkty AJ, Karlowsky JA. Fidaxomicin: a novel agent for the treatment of Clostridium difficile infection. Can J Infect Dis Med Microbiol. 2015;26:305-12.

73. Kelly CR, Khoruts A, Staley C, et al. Effect of fecal microbiota transplantation on recurrence in multiply recurrent Clostridium difficile infection: a randomized trial. Ann Intern Med. 2016;165:609-616.

74. Schlick K, Grundbichler M, Auberger J, et al. Cytomegalovirus reactivation and its clinical impact in patients with solid tumors. Infect Agent Cancer. 2015;10:45.

75. Torres HA, Kontoyiannis DP, Bodey GP, et al. Gastrointestinal cytomegalovirus disease in patients with cancer: a two decade experience in a tertiary care cancer center. Eur J Cancer. 2005;41:2268-79.

76. Alter MJ. Epidemiology of viral hepatitis and HIV co-infection. J Hepatol. 2006;44:S6-9.

77. Wasley A, Kruszon-Moran D, Kuhnert W, et al. The prevalence of hepatitis $B$ virus infection in the United States in the era of vaccination. J Infect Dis. 2010;202:192-201.

78. Averhoff FM, Glass N, Holtzman D. Global burden of hepatitis C: considerations for healthcare providers in the United States. Clin Infect Dis. 2012;55(Suppl 1):S10-5.

79. Hwang JP, Somerfield MR, Alston-Johnson DE, et al. Hepatitis B virus screening for patients with cancer before therapy: American Society of Clinical Oncology provisional clinical opinion update. J Clin Oncol. 2015;33:2212-20.

80. Shouval D, Shibolet O. Immunosuppression and HBV reactivation. Semin Liver Dis. 2013;33:167-77.

81. Weinbaum CM, Williams I, Mast EE, et al. Recommendations for identification and public health management of persons with chronic hepatitis $\mathrm{B}$ virus infection. MMWR Recomm Rep. 2008;57:1-20. 
82. Paul S, Saxena A, Terrin N, Viveiros K, Balk EM, Wong JB. Hepatitis B virus reactivation and prophylaxis during solid tumor chemotherapy: a systematic review and meta-analysis. Ann Intern Med. 2016;164:30-40.

83. Hwang JP, Barbo AG, Perrillo RP. Hepatitis B reactivation during cancer chemotherapy: an international survey of the membership of the American Association for the Study of Liver Diseases. J Viral Hepat. 2015;22:346-52.

84. Hwang JP, Vierling JM, Zelenetz AD, Lackey SC, Loomba R. Hepatitis B virus management to prevent reactivation after chemotherapy: a review. Support Care Cancer. 2012;20:2999-3008.

85. Baden LR, Swaminathan S, Angarone $\mathrm{M}$, et al. Prevention and treatment of cancer-related infections, version 2.2016, NCCN Clinical Practice Guidelines in Oncology. J Natl Compr Cancer Netw. 2016;14:882-913.

86. Torres HA, Mahale P, Blechacz B, et al. Effect of hepatitis $C$ virus infection in patients with cancer: addressing a neglected population. J Natl Compr Cancer Netw. 2015;13:41-50.

87. Mahale P, Kontoyiannis DP, Chemaly RF, et al. Acute exacerbation and reactivation of chronic hepatitis $\mathrm{C}$ virus infection in cancer patients. J Hepatol. 2012;57:1177-85.

88. Borchardt RA, Torres HA. Challenges in managing hepatitis $C$ virus infection in cancer patients. World J Gastroenterol. 2014;20:2771-6.
89. Lee $M H$, Yang HI, Yuan Y, L'Italien G, Chen CJ. Epidemiology and natural history of hepatitis $\mathrm{C}$ virus infection. World J Gastroenterol. 2014;20:9270-80.

90. Yazici O, Sendur MA, Aksoy S. Hepatitis C virus reactivation in cancer patients in the era of targeted therapies. World J Gastroenterol. 2014;20:6716-24.

91. Butt AA, Wang X, Moore CG. Effect of hepatitis C virus and its treatment on survival. Hepatology. 2009;50:387-92.

92. Mira JA, Rivero-Juárez A, López-Cortés LF, et al. Benefits from sustained virologic response to pegylated interferon plus ribavirin in HIV/hepatitis C virus-coinfected patients with compensated cirrhosis. Clin Infect Dis. 2013;56:1646-53.

93. Flukes S, Hayne D, Kuan M, Wallace M, McMillan K, Rukin NJ. Retrograde ureteric stent insertion in the management of infected obstructed kidneys. BJU Int. 2015;115(Suppl 5):31-4.

94. Benson AD, Taylor ER, Schwartz BF. Metal ureteral stent for benign and malignant ureteral obstruction. J Urol. 2011;185:2217-22.

95. Goldsmith ZG, Wang AJ, Bañez LL, et al. Outcomes of metallic stents for malignant ureteral obstruction. J Urol. 2012;188:851-5.

96. de Naurois J, Novitzky-Basso I, Gill MJ, et al. Management of febrile neutropenia: ESMO Clinical Practice Guidelines. Ann Oncol. 2010;21(Suppl 5):v252-6. 